\title{
Sex Differences in Insular Cortex Gyri Responses to the Valsalva Maneuver
}

\section{Paul M. Macey ${ }^{1,2 *}$, Nicholas S. Rieken', Rajesh Kumar ${ }^{2,3,4}$, Jennifer A. Ogren ${ }^{5}$, Holly R. Middlekauff', Paula Wu ${ }^{5,7}$, Mary A. Woo ${ }^{1}$ and Ronald M. Harper ${ }^{2,5}$}

1 UCLA School of Nursing, University of California at Los Angeles, Los Angeles, CA, USA, ${ }^{2}$ Brain Research Institute, University of California at Los Angeles, Los Angeles, CA, USA, ${ }^{3}$ Department of Anesthesiology, University of California at Los Angeles, Los Angeles, CA, USA, ${ }^{4}$ Department of Radiological Sciences, University of California at Los Angeles, Los Angeles, CA, USA, ${ }^{5}$ Department of Neurobiology, University of California at Los Angeles, Los Angeles, CA, USA, ${ }^{6}$ Department of Medicine, Division of Cardiology, David Geffen School of Medicine, University of California at Los Angeles, Los Angeles, CA, USA, ${ }^{7}$ Yale School of Medicine, Yale University, New Haven, CT, USA

Sex differences in autonomic regulation may underlie cardiovascular disease variations between females and males. One key autonomic brain region is the insular cortex, which typically consists of five main gyri in each hemisphere, and shows a topographical organization of autonomic function across those gyri. The present study aims to identify possible sex differences in organization of autonomic function in the insula. We studied brain functional magnetic resonance imaging (fMRI) responses to a series of four 18-s Valsalva maneuvers in 22 healthy females (age \pm SD: $50.0 \pm 7.9$ years) and 36 healthy males $(45.3 \pm 9.2$ years). Comparisons of heart rate $(H R)$ and $f M R I$ signals were performed with repeated measures ANOVA (threshold $P<0.05$ for all findings). All subjects achieved the target $30 \mathrm{mmHg}$ expiratory pressure for all challenges. Typical HR responses were elicited by the maneuver, including HR increases from 4 s into the strain period (Phase II) and rapid declines to below baseline 5-10 s, following strain release (Phase IV). Small, but significant, sex differences in HR percent change occurred during the sympathetic-dominant Phase II (female < male) and parasympathetic-dominant Phase IV (female > male, i.e., greater undershoot in males). The insular cortices showed similar patterns in all gyri, with greater signal decreases in males than females. Both sexes exhibited an anterior-posterior topographical organization of insular responses during Phase II, with anterior gyri showing higher responses than more posterior gyri. The exception was the right anterior-most gyrus in females, which had lower responses than the four other right gyri. Responses were lateralized, with right-sided dominance during Phase II in both sexes, except the right anterior-most gyrus in females, which showed lower responses than the left. The findings confirm the anterior and rightsided sympathetic dominance of the insula. Although sex differences were prominent in response magnitude, organization differences between males and females were limited to the right anterior-most gyrus, which showed a lower fMRI response in females vs. males (and vs. other gyri in females). The sex differences suggest a possible differing baseline state of brain physiology or tonic functional activity between females and males, especially in the right anterior-most gyrus.

Keywords: autonomic, sympathetic, fMRI, cardiovascular, functional neuroanatomy 


\section{INTRODUCTION}

Sex differences in cardiovascular and other diseases may be driven in part by variations in autonomic nervous system function; identifying the neural source of such differences may improve understanding of mechanisms and potential treatment options. While many sex differences in cardiovascular function vary by age, with substantial variations between pre- and postmenopausal women, there nevertheless remain distinct characteristics of females compared with males $(1,2)$. For example, males show a higher prevalence of hypertension than females (3-5), but prognoses for women after myocardial infarction are worse than for males $(6,7)$. Such clinical sex differences are associated with autonomic function variation, including reduced muscle sympathetic nerve activity (MSNA) in women $(8,9)$, lower resting heart rate (HR) in men, differing HR variability patterns (10), sex differences in catecholamine responses to central sympathetic inhibition (11), and lower baroreflex sensitivity in females [(12); for review, see Dart et al. (13)]. One possibility is that enhanced alterations in sympatho-adrenal activation in males compared with females reflect greater sympathetic nervous system control in females, which is protective against hypertension and other cardiovascular disease (14). Many neural structures associated with autonomic functions show sex differences in function or structure at cellular and anatomical scales $(15,16)$. Brain regions serving autonomic regulation are potential therapeutic targets for interventions, but further understanding of sex differences in autonomic function of such regions is required.

The insular cortex is one key autonomic regulatory structure located under the parietal operculum and within the lateral sulcus (17-20). The insula receives input from multiple cortical areas involved with emotional, cognitive, and sensorimotor functions and projects to autonomic outflow areas in the brainstem both directly and via the hypothalamus (21-24). Although the insular cortices may not be involved in tonic maintenance of blood pressure (25), stimulation, stroke, lesion, resection, and MRI studies in human and non-human models provide evidence which demonstrates that those cortical areas serve roles in autonomic regulation $(20,25-39)$. The gyri of the insula are organized in a ventrodorsal orientation (18). Functions are topographically organized, in both human and non-human primates, with autonomic regulation, in particular, showing differentiation over the major gyri (40-46). However, the topographic differentiation of autonomic function by sex is unclear. Sex differences in spatial organization of insular function could contribute to sex differences in physiologic autonomic regulation (47).

Altered functions could arise from differences in structure. Males show larger insulae, with on average more gyral folding than females $(16,48)$. Larger brain weight and volume in males are consistent macroscopic findings, although one accounted for by their larger body dimensions $(15,49-51)$. Distribution of gray and white matter brain tissue compartments shows sex differences when adjusted for individual brain size (51-57). A recent meta-analysis of raw mean brain volumes for typically developing females and males found that the right insular cortex, right anterior cingulate gyrus, and bilateral thalamus gray matter densities were greater in female subjects, whereas the left anterior and posterior cingulate gyri and the right and left amygdalae have greater gray matter volume in male subjects (58).

The topographic organization of autonomic functions in the insula can be evaluated with functional magnetic resonance imaging (fMRI) during physiological challenges. One such stimulus is the Valsalva maneuver $(44,59)$, a standard test of autonomic function involving a forced expiratory effort against a closed glottis, resulting in increased thoracic pressure (60-63). The physiologic responses to the Valsalva consist of four phases, with different recruitment of parasympathetic and sympathetic systems, and the task allows differentiation of various components of the autonomic response, with amplitude and timing patterns that might differentiate sex roles (64-66). Phase II is the strain period 3-5 s after initiation of the challenge and is characterized by strong sympathetic activation, indicated by an increasing $\operatorname{HR}(67,68)$. Sympathetic withdrawal follows in the Phase IV recovery period $3-5 \mathrm{~s}$ after pressure release, characterized by a rapid HR fall to levels below baseline, followed by a gradual return over minutes to starting levels (69-71). Variations from the normal response occur in people with impaired autonomic regulation (72).

The objective was to assess female and male insular gyral organization of fMRI responses to the Valsalva maneuver in healthy adults. We evaluated both anterior-posterior organization within left and right insular cortices, and the laterality of equivalent gyri, since the right insula has been shown to be dominant during sympathetic phases of autonomic stimuli (44); animal and human models also show a preferentially sympathetic role for the right insula (73-76). Based on sex differences in central and peripheral autonomic function, we hypothesized that insular organization would differ between the sexes. Based on greater cell densities in females, we hypothesized males would show lower magnitudes of responses than females. Based on the lower metabolism in females in the anterior insula, we hypothesize that the short gyri would show more substantial sex differences compared with the long gyri.

\section{MATERIALS AND METHODS}

\section{Subjects}

We studied 57 healthy adults (age \pm SD: $47.0 \pm 9.1$ years, range: 31-66 years; 37 males, 20 females). All subjects had no history of cerebrovascular disease, myocardial infarction, heart failure, neurological disorders, or mental illness and were not taking cardiovascular or psychotropic medications. Subjects were recruited from the Los Angeles area and did not weigh more than $125 \mathrm{~kg}$ or have any metallic or electronic implants; the latter two issues are MRI scanner contraindications. All subjects provided written informed consent in accordance with the Declaration of Helsinki, and the research protocol was approved by the Institutional Review Board of UCLA. No subjects were taking exogenous sex hormones (for example, oral contraceptive pills, hormone replacement therapy, or testosterone therapy).

\section{Valsalva Maneuver}

The Valsalva maneuver was performed in a sequence of four 18-s exhalations against a closed glottis, spaced $1 \mathrm{~min}$ apart, to a target 
expiratory pressure of $30 \mathrm{mmHg}$ (77). While $40 \mathrm{mmHg}$ for $20 \mathrm{~s}$ is commonly used, we selected slightly lower pressure and duration to help ensure the task could be successfully performed by a wide range of subjects of differing age and health. A light signal was used to indicate onset of the challenge for the Valsalva effort to the subject. Subjects were instructed to, upon seeing the light signal, take a breath and exhale against a resistance, maintaining a target pressure. A second light was illuminated when the subject achieved this $30 \mathrm{mmHg}$ target pressure. Subjects practiced the Valsalva maneuver prior to scanning, and the research team observed each challenge to ensure the target pressure was reached and maintained for each of the four expiratory periods.

\section{Physiologic Signals}

Cardiac, load pressure and indicator signals (e.g., light on/off) were recorded with an analog-to-digital acquisition system (instruNet INET-100B, GWI Instruments, Inc., Somerville, MA, USA). HR was assessed using an MRI-compatible pulse oximeter (Nonin Medical Inc., Plymouth, MN, USA). The sensor was placed on the right index finger throughout the scan, and HR was calculated from the raw oximetry signal acquired at $1 \mathrm{kHz}$ using custom peak-detection software followed by expert review. Expiratory pressure was measured via tubing connected to a pressure sensor (Omega Engineering Inc., Stamford, CT, USA) outside the scanner. Patient cue signals were simultaneously recorded, and all signals were synchronized to the MRI scans and data corresponding to the fMRI recording period extracted.

\section{MRI Scanning}

Functional MRI scans were acquired using a 3.0-T scanner (Siemens Magneton Tim-Trio, Erlangen, Germany), while subjects lay supine. A foam pad was placed on either side of the head to minimize movement. We collected whole-brain images with the blood oxygen-level-dependent (BOLD) contrast [repetition time $(\mathrm{TR})=2000 \mathrm{~ms}$; echo time $(\mathrm{TE})=30 \mathrm{~ms}$; flip angle $=90^{\circ}$; matrix size $=64 \times 64$; field-of-view $=220 \mathrm{~mm} \times 220 \mathrm{~mm}$; slice thickness $=4.5 \mathrm{~mm}]$. The spatial resolution was based on achieving whole-brain coverage with the fastest possible acquisition time. Two high-resolution, T1-weighted anatomical images were also acquired with a magnetization prepared rapid acquisition gradient echo sequence $(\mathrm{TR}=2200 \mathrm{~ms}$; $\mathrm{TE}=2.2 \mathrm{~ms}$; inversion time $=900 \mathrm{~ms}$; flip angle $=9^{\circ}$; matrix size $=256 \times 256$; field-of-view $=230 \mathrm{~mm} \times 230 \mathrm{~mm}$; slice thickness $=1.0 \mathrm{~mm}$ ). Field map data consisting of phase and magnitude images were collected to allow for correction of distortions due to field inhomogeneities.

\section{MRI Data Preprocessing}

All anatomical scans were inspected to ensure the absence of visible pathology. For each fMRI series, the global signal was calculated and the images realigned to account for head motion. Subjects with large changes in global BOLD signal, or who moved more than $4 \mathrm{~mm}$ in any direction were not included in the study. Each fMRI series was linearly detrended to account for signal drift (but not global effects) (78) and corrected for field inhomogeneities, spatially normalized, and smoothed (8-mm Gaussian filter), and mean time trends from each voxel were calculated across all subjects, as well as the challengemeans across each of the four Valsalva periods. A mean image of all subjects' spatially normalized, anatomic scans was created. Software used included the statistical parametric mapping package, SPM12 (Wellcome Department of Cognitive Neurology, UK; www.fil.ion.ucl.ac.uk/spm), MRIcron (79), and MATLABbased custom software.

\section{Region of Interest Tracing}

The five major gyral regions in the insular cortex, the anterior short gyrus (ASG), mid short gyrus (MSG), posterior short gyrus (PSG), anterior long gyrus (ALG), and posterior long gyrus (PLG), were outlined on the mean anatomical image with MRIcroN software (79), using previously published anatomical descriptions $(18,80)$. Figure 1 illustrates the gryi on an average anatomical scan in sagittal and axial views. While individual tracing would be more accurate for identifying the gyral differentiation on anatomical scans, the fMRI data are at a much lower spatial resolution (voxel volume of 53 vs. $0.8 \mathrm{~mm}^{3}$ for the

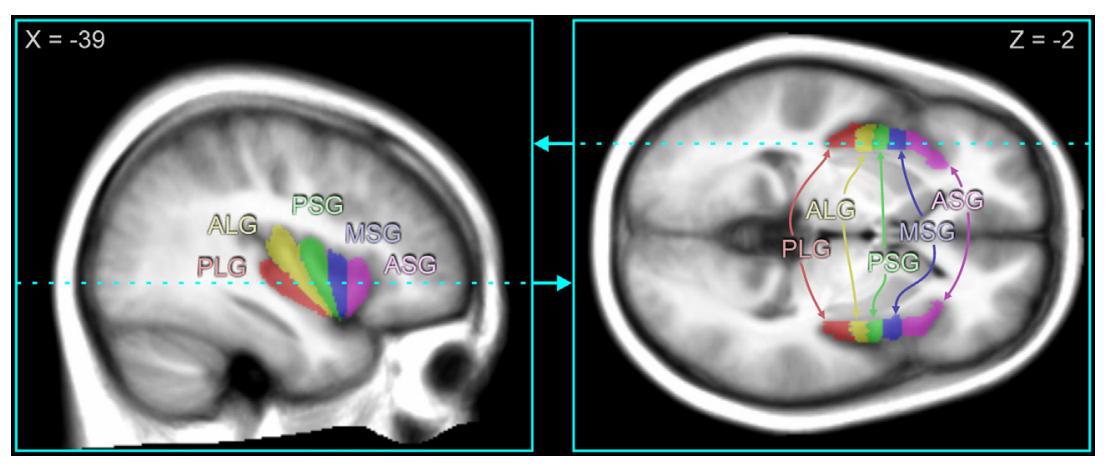

FIGURE 1 | Insular gyri color-coded and overlaid on average anatomical scan. The anterior region of the insula is comprised of the short gyri, including the anterior short gyrus (ASG), mid short gyrus (MSG), and posterior short gyrus (PSG). The posterior region of the insula is comprised of the long gyri, including the anterior long gyrus (ALG) and posterior long gyrus (PLG). Coordinates in MNI space are indicated for each slice, and the slice location of the axial view is shown by the dashed line on the sagittal view and vice versa. 
anatomical scans), and the BOLD effect itself, which is the basis for assessing neuronal responses, is diffuse, so the advantage of individual tracing would be minimal. Since gyral folding in the insula has individual variation (48), the present approach distinguishes gyral regions rather than gyri per se. The three main gyri of the anterior insula, the ASG, MSG, and PSG, make up the convex surface of the structure and are visible on the sagittal and axial views of the mean anatomical image. The accessory and transverse gyri, two other gyri in the anterior insula, are difficult to visualize (80) and were not visible on the mean anatomical image. Thus, in our tracing of the ASG, we included the entire most-anterior portion of the insula, which included the accessory and transverse gyri. The posterior gyri (ALG and PLG) were easily visible on sagittal and axial sections of the anatomical volume.

\section{Statistical Analysis}

Repeated measures ANOVA (RMANOVA), implemented with the mixed linear model procedure "proc mixed" in SAS 9.4 software (81), was used to identify periods of significant response relative to baseline, during the Valsalva and subsequent recovery periods (82). We modeled the fMRI responses as a function of scan timepoints. Significance was first assessed at the global level; as per the Tukey-Fisher criterion for multiple comparisons, the timepoints of significant responses were identified only for significant models $(P<0.05)$. Three sets of models were created: (1) within and between-group analyses of fMRI signal change relative to baseline; (2) separate female and male between-group signal change relative to PLG, where group consistent of five gyri in one hemisphere (with six between-gryi comparisons each); and (3) separate female and male signal change of left relative to right gyrus. Statistical assessment of sex differences for (2) and (3) were not performed as those signals were relative to another gyrus, such that the signal in males was relative to a different reference than females, which would complicate interpretation of RMANOVA-identified female and male differences. To avoid potential confounds due to global vascular effects, we focused on relative changes between gyri. The restriction of only assessing differences, rather than absolute responses, results from the relative nature of the BOLD-based fMRI technique. To identify anterior-posterior organization, we assessed responses with respect to the PLG, as the posterior insula typically responds less than anterior regions in response to autonomic stimuli (83). To identify lateral organization, we assessed right-sided relative to left-sided responses for each gyrus (44). We did not include a hemisphere factor in any model since the aims were restricted to identifying gyral-specific differences. Since age is a potentially confounding factor, especially in females given the changes in autonomic function associated with menopausal status (84), we implemented each RMANOVA model both with and without age as a covariate.

\section{RESULTS}

\section{Subjects}

Females were, on average, slightly older than males (mean age \pm SD: female $50.0 \pm 7.9$ years; male $45.3 \pm 9.2$ years), although the difference was not significant $(P=0.06$, independent samples $t$-test). Body mass index also did not differ significantly (female $24.0 \pm 5.1 \mathrm{~kg} / \mathrm{m}^{2}$, male $25.2 \pm 2.7 \mathrm{~kg} / \mathrm{m}^{2}$; group difference $P=0.24$, independent samples $t$-test). Six females reported being left-handed, two ambidextrous, and 14 right-handed. Four males reported being left-handed, two ambidextrous, and 30 righthanded. The difference was not significant $(P=0.2$, chi-squared).

\section{Physiology}

The average HR changes in females and males illustrate the typical pattern of autonomic responses elicited by the Valsalva (Figure 2). The initial HR increase results from full inspiration prior to the forceful expiration, which leads to brief HR increases as compensation for the thoracic pressure changes, a period termed Phase 0 (85). While there were significant differences between females and males, notably smaller relative HR increases during Phase II and reduced undershoot in Phase IV, the magnitude of those differences was small, and both sexes showed the same pattern of responses (Figure 2A). The absolute levels show the expected higher HR in females over males (Figure 2B), and visual inspection of the sequence of four Valsalva challenges shows similar responses over the repeated maneuvers (Figure 2B).

Both groups showed a decrease in oxygen saturation $\left(\mathrm{SaO}_{2}\right)$ from $10 \mathrm{~s}$ into the challenge, with a return toward baseline beginning $\sim 8 \mathrm{~s}$ into the recovery period. The $\mathrm{SaO}_{2}$ was slightly higher in females than males during baseline and recovery periods (Figures 2C,D). However, females showed a greater decline during and after the challenge, such that the values were similar during the low $\mathrm{SaO}_{2}$ period. Female recovery was also larger, with an overshoot peaking $20 \mathrm{~s}$ into the recovery period, whereas males showed a flat response.

\section{fMRI Responses}

The Valsalva maneuver elicited significant fMRI signal responses during the expiration period that differed from baseline in all gyri in both sexes (Figure 3). For both males and females, significant within-group responses were present throughout the strain period and during the recovery (blue X's and red O's in Figure 3).

Female and male responses differed in all gyri (Table 1; Figure 3). While the patterns included increases and decreases relative to baseline, the magnitude of female responses was consistently higher than males throughout the Valsalva period, as shown by the higher group averages (that is, the solid female lines higher than dashed male lines). Group differences were present from $4 \mathrm{~s}$ into the challenge, shortly after the start of the strain period ( $P<0.05$, RMANOVA red-yellow stars in Figure 3 ). The differences remained through to the end of the strain period, with the exception of the right ASG, where there were no differences from timepoints 8-12 s. The sex difference remained up to the first timepoint after the strain in the left ASG and in all posterior gyri (bilateral PSG, ALG, and PLG). The MSG showed no group difference during recovery.

\section{Anterior-Posterior Organization}

Although most functional organization in terms of anteriorposterior and left-right relative responses was similar to the 


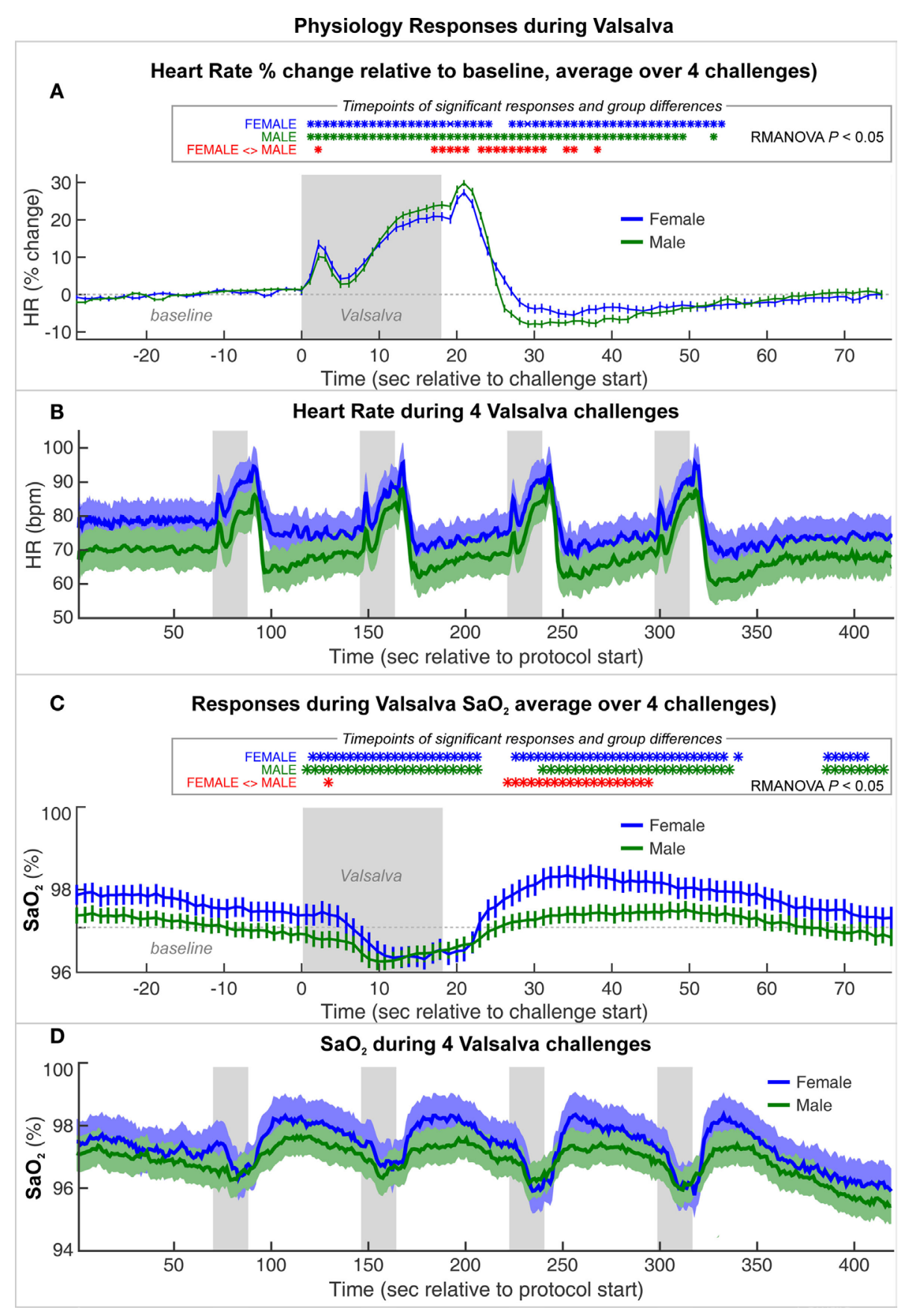

FIGURE 2 | Heart rate (HR) and $\mathrm{SaO}_{2}$ changes during a series of four Valsalva maneuvers, averaged for female and male groups. (A) HR\% change relative to baseline and $\mathbf{( C )} \mathrm{SaO}_{2}$ averaged over four challenges (mean $\pm \mathrm{SE}$ ). Timepoints of significant within-group responses indicated in blue and green *, and significant group differences in red, based on $P<0.05$ with repeated measures ANOVA (RMANOVA). (B) Absolute heart rate and (D) SaO ${ }_{2}$ over series of four Valsalva maneuvers, averaged over females and males with SE shaded.

mixed group findings, differences appeared by sex, especially in the anterior insula (Table 2; Figure 4). An anterior-posterior organization was evident in the left insula, with ASG > MSG, MSG > PSG, and PSG > ALG. The organization of these four anterior-most gyri was similar in females and males, with significant differences between the regions during the expiratory period
$(P<0.05$, RMANOVA). However, the PLG in males showed a similar magnitude of response to the ALG, whereas in females, the PLG showed a magnitude between those of the MSG and PSG. In both sexes, the ASG demonstrated an elevated response relative to other gyri throughout most of the strain period (timepoints 4-18 s), with the MSG also showing a sustained, higher 


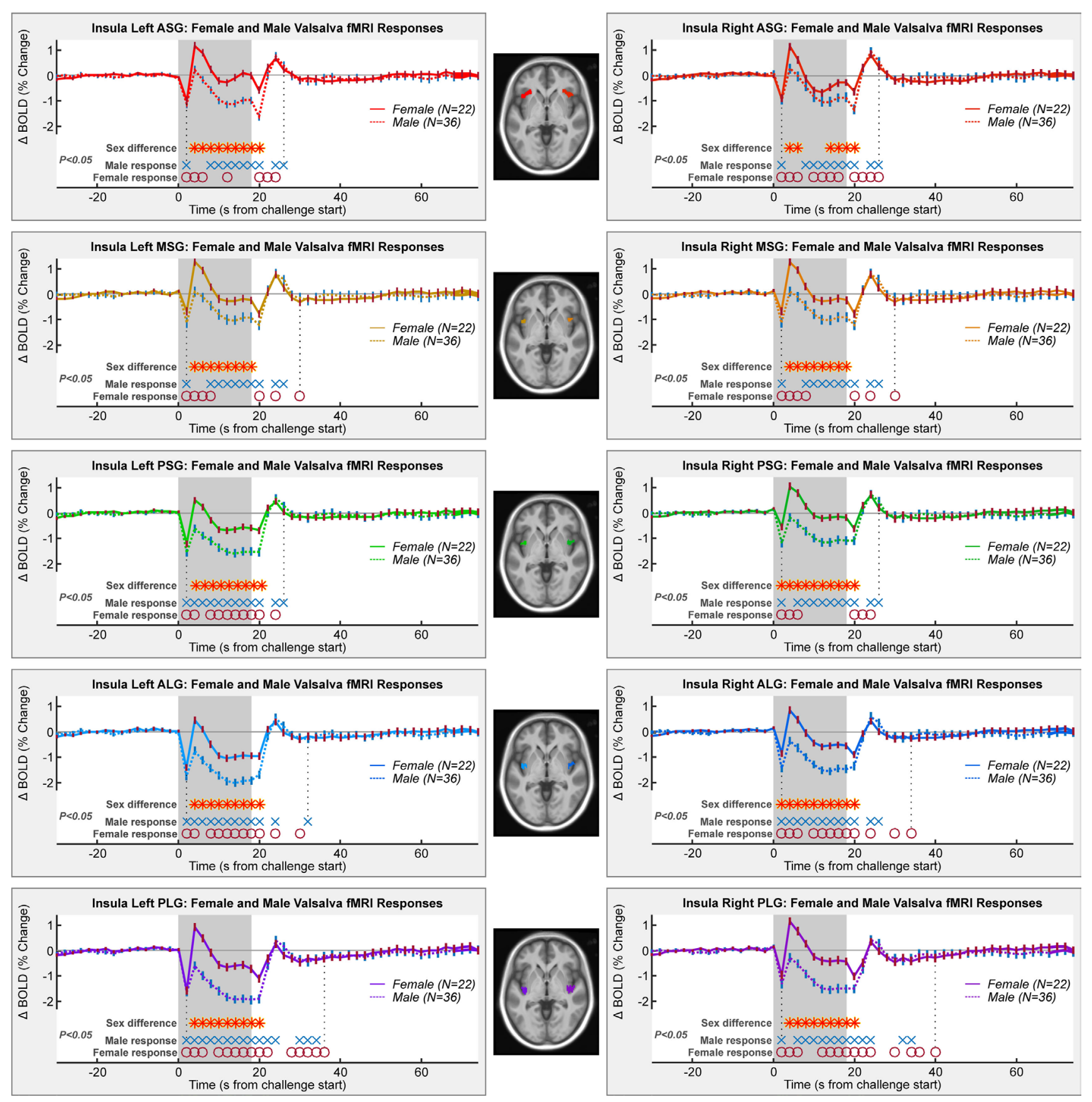

FIGURE 3 | Mean fMRI insula responses over four Valsalva maneuvers, averaged for female and male groups. All left and right gyri patterns are shown. Timepoints of significant within-group responses and between-group differences are indicated above the $x$-axis and below the graphs (RMANOVA, $P<0.05)$.

response relative to more posterior gyri. The same was true for the PSG relative to the ALG, and in males, the PSG relative to the PLG. In females, the PSG displayed significantly lower activity than the PLG for 6-10 s during the challenge. To summarize the left-sided patterns, males: ASG > MSG, MSG > PSG, PSG > PLG; females: ASG $\geq$ MSG, MSG $>$ PSG, PSG $\leq$ PLG.

The right insula showed an anterior-posterior organization in males, although the ASG and MSG neither differ significantly nor did the ALG and PLG; the PSG responses were between these pairs of regions. In females, the right insular organization differed from that in males. The MSG and PSG were modestly higher than the PLG for half the strain period (6-14 s), whereas the ASG showed the lowest response in conjunction with the ALG. To summarize the right-sided patterns, females: MSG, PSG, PLG > ASG, ALG; males: ASG, MSG > PSG > ALG, PLG. 
TABLE 1 | Female vs. male model fit with and without age.

\begin{tabular}{|c|c|c|c|c|}
\hline Female vs. male & $\begin{array}{l}\text { Group, } \\
\text { time }\end{array}$ & $\begin{array}{l}\text { Group, } \\
\text { time, age }\end{array}$ & $\begin{array}{l}\text { Group, } \\
\text { time }\end{array}$ & $\begin{array}{l}\text { Group, } \\
\text { time, age }\end{array}$ \\
\hline & Left ASG & & Right ASG & \\
\hline $\begin{array}{l}\text { Model ChiSq } \\
(P<0.0001)\end{array}$ & 454.28 & 456.57 & 600.52 & 603.27 \\
\hline-2 log likelihood & 6925.1 & 6933.8 & 7856.9 & 7864.6 \\
\hline Group $(P)$ & 0.0028 & 0.0055 & 0.1888 & 0.3167 \\
\hline Time $(P)$ & $<0.0001$ & $<0.0001$ & $<0.0001$ & $<0.0001$ \\
\hline Group $\times$ time $(P)$ & $<0.0001$ & $<0.0001$ & 0.0066 & 0.0066 \\
\hline \multirow[t]{2}{*}{ Age $(P)$} & & 0.6743 & & 0.2882 \\
\hline & Left MSG & & Right MSG & \\
\hline $\begin{array}{l}\text { Model ChiSq } \\
(P<0.0001)\end{array}$ & 584.48 & 586.86 & 651.88 & 653.42 \\
\hline -2 log likelihood & 6852.1 & 6860.5 & 8158.7 & 8166.1 \\
\hline Group $(P)$ & 0.0018 & 0.0045 & 0.067 & 0.1356 \\
\hline Time $(P)$ & $<0.0001$ & $<0.0001$ & $<0.0001$ & $<0.0001$ \\
\hline Group $\times$ time $(P)$ & $<0.0001$ & $<0.0001$ & $<0.0001$ & $<0.0001$ \\
\hline Age $(P)$ & & 0.4375 & & 0.2354 \\
\hline $\begin{array}{l}\text { Model ChiSq } \\
(P<0.0001)\end{array}$ & $\begin{array}{l}\text { Left PSG } \\
647.74\end{array}$ & 648.73 & $\begin{array}{c}\text { Right PSG } \\
583.37\end{array}$ & 584.68 \\
\hline-2 log likelihood & 7070.9 & 7079.7 & 7519.7 & 7526.6 \\
\hline Group $(P)$ & 0.01 & 0.0121 & 0.0046 & 0.0175 \\
\hline Time $(P)$ & $<0.0001$ & $<0.0001$ & $<0.0001$ & $<0.0001$ \\
\hline Group $\times$ time $(P)$ & $<0.0001$ & $<0.0001$ & $<0.0001$ & $<0.0001$ \\
\hline \multirow[t]{2}{*}{ Age $(P)$} & & 0.8809 & & 0.1001 \\
\hline & Left ALG & & Right ALG & \\
\hline $\begin{array}{l}\text { Model ChiSq } \\
(P<0.0001)\end{array}$ & 590.5 & 587.09 & 563.75 & 567.05 \\
\hline -2 log likelihood & 7141.1 & 7149.4 & 7171 & 7178.4 \\
\hline Group $(P)$ & 0.0071 & 0.0065 & 0.0056 & 0.0175 \\
\hline Time $(P)$ & $<0.0001$ & $<0.0001$ & $<0.0001$ & $<0.0001$ \\
\hline Group $\times$ time $(P)$ & $<0.0001$ & $<0.0001$ & $<0.0001$ & $<0.0001$ \\
\hline \multirow[t]{2}{*}{ Age $(P)$} & & 0.5751 & & 0.1769 \\
\hline & Left PLG & & Right PLG & \\
\hline $\begin{array}{l}\text { Model ChiSq } \\
(P<0.0001)\end{array}$ & 497.41 & 491.5 & 519.91 & 521.1 \\
\hline-2 log likelihood & 7745 & 7753.2 & 7907.3 & 7915.6 \\
\hline Group $(P)$ & 0.001 & 0.0009 & 0.003 & 0.0064 \\
\hline Time $(P)$ & $<0.0001$ & $<0.0001$ & $<0.0001$ & $<0.0001$ \\
\hline Group $\times$ time $(P)$ & $<0.0001$ & $<0.0001$ & $<0.0001$ & $<0.0001$ \\
\hline Age $(P)$ & & 0.4667 & & 0.5565 \\
\hline
\end{tabular}

Overall model chi square (ChiSq) was always significant $(P<0.0001)$. The model fit is indicated by $-2 \times \log$ likelihood as calculated by SAS (higher indicates better fit). The $P$ values for each variable are shown; group $\times$ time and time were significant $(P<0.05)$ in all cases, and age was not significant in any model.

\section{Left-Right Organization}

Lateralization of activity during the challenge was evident in all gyri with the exception of the ASG in males and MSG in females (Table 3; Figure 5). However, the pattern of lateralization differed between sexes. Males showed greater activity in the right over left throughout the expiratory period in all gyri except the ASG. Females showed similar sustained greater activity in right vs. left in long gyri and PSG. In the MSG, there was no significant effect (Table 3). In the ASG, females showed the opposite pattern to males and other gyri, namely, a signal decrease in right vs. left during the expiratory phase.

\section{Age Influences}

Inclusion of age in the models testing above did not alter the significance of group, time, or group by time variables (Tables 1-3).
TABLE 2 | Anterior-posterior model fit with and without age.

\begin{tabular}{|c|c|c|c|c|}
\hline $\begin{array}{l}\text { Anterior vs. } \\
\text { posterior }\end{array}$ & $\begin{array}{l}\text { Group, } \\
\text { time }\end{array}$ & $\begin{array}{l}\text { Group, } \\
\text { time, age }\end{array}$ & $\begin{array}{l}\text { Group, } \\
\text { time }\end{array}$ & $\begin{array}{l}\text { Group, } \\
\text { time, age }\end{array}$ \\
\hline $\begin{array}{l}\text { Model ChiSq } \\
(P<0.0001)\end{array}$ & $\begin{array}{c}\text { Female left } \\
482.01\end{array}$ & 457.29 & $\begin{array}{c}\text { Female right } \\
649.76\end{array}$ & 622.13 \\
\hline -2 log likelihood & 5787.5 & 5793.2 & 4660.4 & 4665.9 \\
\hline Group $(P)$ & 0.0001 & 0.0001 & 0.0189 & 0.0153 \\
\hline Time $(P)$ & $<0.0001$ & $<0.0001$ & $<0.0001$ & $<0.0001$ \\
\hline $\begin{array}{l}\text { Group } \times \text { time }(P) \\
\text { Age }(P)\end{array}$ & $<0.0001$ & $\begin{array}{c}<0.0001 \\
0.0309\end{array}$ & $<0.0001$ & $\begin{array}{c}<0.0001 \\
0.024\end{array}$ \\
\hline $\begin{array}{l}\text { Model ChiSq } \\
(P<0.0001)\end{array}$ & $\begin{array}{l}\text { Male left } \\
1147.24\end{array}$ & 1113.27 & $\begin{array}{c}\text { Male right } \\
1118.85\end{array}$ & 1110.22 \\
\hline-2 log likelihood & 9826.7 & 9833.6 & 6499.1 & 6509.9 \\
\hline Group $(P)$ & $<0.0001$ & $<0.0001$ & $<0.0001$ & $<0.0001$ \\
\hline Time $(P)$ & $<0.0001$ & $<0.0001$ & $<0.0001$ & $<0.0001$ \\
\hline $\begin{array}{l}\text { Group } \times \text { time }(P) \\
\text { Age }(P)\end{array}$ & $<0.0001$ & $\begin{array}{c}<0.0001 \\
0.0486\end{array}$ & $<0.0001$ & $\begin{array}{c}<0.0001 \\
0.3716\end{array}$ \\
\hline
\end{tabular}

Overall model chi square (ChiSq) was always significant $(P<0.0001)$. The model fit is indicated by $-2 \times \log$ likelihood as calculated by SAS (higher indicates better fit). The $P$ values for each variable are shown; group $\times$ time was significant $(P<0.05)$ in all cases, and age was significant for all models apart from male right.

In all models, the inclusion of age slightly improved the model fit as indicated by higher chi square and -2 log likelihood values. As a variable in these models, age was only significant in anterior-posterior comparisons, on both sides in females and on the left only in males.

\section{Summary of Key Finding: Sex Differences in Right ASG}

Comparison of ASG responses in Figures $\mathbf{3}$ and $\mathbf{4}$ show that male and female responses in the right ASG show the most substantial differences of any region, leading to both lateralization and anterior-posterior organization differences in the ASG region. These substantial sex differences in both magnitudes and patterns of fMRI signals occurred, despite only moderate variations in HR responses to the Valsalva maneuver.

We made available summary data including RMANOVA models and results, figures, and preprocessed fMRI images in a repository (86); the full raw dataset could not be provided to due the consent acquired at the time.

\section{DISCUSSION}

\section{Overview}

Responses in both the right and left insular cortices during the strain phase of the Valsalva maneuver differed between sexes, with larger magnitude fMRI signal declines in males over females in all gyri. Similar anterior-posterior distributions of activity appeared in both males and females. Lateralization showed a right-sided dominance during the strain phase in all gyri in males, and in all but the anterior-most ASG in females, consistent with the right-sided sympathetic dominance previously reported (73). Thus, the most notable differences between sexes were the magnitude of response and the unique responses in females in the right ASG. These male-female differences in insular function 

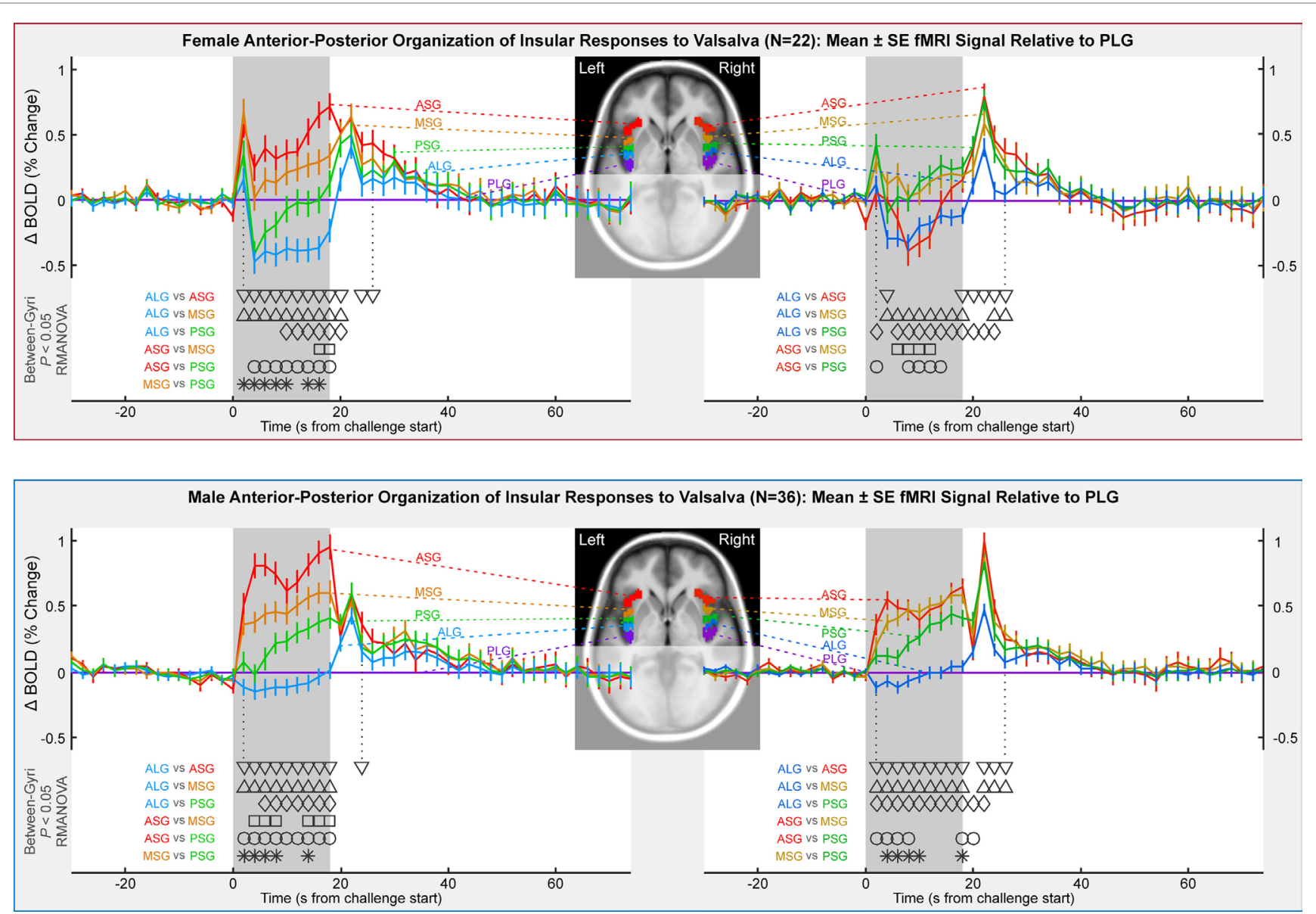

FIGURE 4 | Anterior-to-posterior organization of insula fMRI responses over four Valsalva maneuvers, illustrated by timetrends relative to pattern in posterior-most gyrus (PLG). Females in top and males in bottom. Timepoints of between-gyral differences are indicated by symbols above the $x$-axis and below the graphs (RMANOVA, $P<0.05$ ).

may contribute to sex differences in cardiac responses to autonomic challenges and, over time, cardiovascular disease. The strain phase of the Valsalva is characterized by a large and rapid increase in sympathetic activity, as reflected in the HR increase; thus, the general findings corroborate the more anterior location of autonomic control within the insula.

\section{Insular Role in Regulation: fMRI and Physiology}

Heart rate changes exhibited a typical pattern for healthy adults, with only minor sex differences, consistent with other findings (87). The fMRI time course in males and females followed an approximate inverse relationship with the HR changes, with brief insular deactivations at inspiration and beginning of expiration, declines during the sympathetic Phase II, a brief trough after release, followed by an overshoot and return to baseline in Phase IV (47). Oxygen saturation decreased in the latter half of Phase II and remained low for $\sim 8 \mathrm{~s}$ following recovery, with a rebound in $\sim 15 \mathrm{~s}$ into Phase IV; the oxygenation changes likely reflect lack of ventilation during breath-hold then higher ventilation after termination of the Valsalva. The fMRI signals did not appear to follow the oxygenation saturation patterns. While the fMRI changes could reflect a sensory role, with neural responses based on blood pressure and related afferent signals, human stroke and animal stimulation studies suggest the structure participates in regulation of autonomic functions $(24,74,88-90)$. In particular, the observed pattern is consistent with the insula having an inhibitory role on HR changes. However, the insula does not show the exact opposite pattern to the HR changes since the functional role in cardiovascular regulation is more complex than a direct, proportional inhibition. The fMRI signals in all gyri return to baseline levels relatively early in Phase IV (which can last several minutes), suggesting the structure is not involved in sustaining sympathetic withdrawal. The insula has projections to the hypothalamus, a key autonomic region closely linked with medullary outflow areas $(91,92)$, as with other cortical areas, the insula shows inhibitory roles over lower brain regions (93). However, the male participants consistently showed greater insula declines in fMRI compared with females, even though HR changes were similar; in other words, the differences in magnitude of insula response did not lead to a difference in HR changes, 
TABLE 3 | Left vs. right model fit with and without age.

\begin{tabular}{|c|c|c|c|c|}
\hline $\begin{array}{l}\text { Right vs. } \\
\text { left vs. male }\end{array}$ & $\begin{array}{l}\text { Group, } \\
\text { time }\end{array}$ & $\begin{array}{l}\text { Group, } \\
\text { time, age }\end{array}$ & $\begin{array}{l}\text { Group, } \\
\text { time }\end{array}$ & $\begin{array}{l}\text { Group, } \\
\text { time, age }\end{array}$ \\
\hline & Female ASG & & Male ASG & \\
\hline $\begin{array}{l}\text { Model ChiSq } \\
(P<0.0001)\end{array}$ & 168.98 & 157.17 & 427.43 & 421.36 \\
\hline -2 log likelihood & 1725.5 & 1732.2 & 3132.8 & 3140.6 \\
\hline Time $(P)$ & 0.0002 & 0.0002 & 0.743 & 0.743 \\
\hline Age $(P)$ & & 0.2305 & & 0.4202 \\
\hline $\begin{array}{l}\text { Model ChiSq } \\
(P<0.0001)\end{array}$ & $\begin{array}{l}\text { Female MSG } \\
145.47\end{array}$ & 137.54 & $\begin{array}{l}\text { Male MSG } \\
267.25\end{array}$ & 248.68 \\
\hline -2 log likelihood & 1822.5 & 1829.5 & 3516.3 & 3522.7 \\
\hline Time $(P)$ & 0.0875 & 0.0875 & $<0.0001$ & $<0.0001$ \\
\hline Age $(P)$ & & 0.2834 & & 0.1318 \\
\hline $\begin{array}{l}\text { Model ChiSq } \\
(P<0.0001)\end{array}$ & $\begin{array}{l}\text { Female PSG } \\
196.2\end{array}$ & 161.88 & $\begin{array}{l}\text { Male PSG } \\
207.28\end{array}$ & 186.97 \\
\hline -2 log likelihood & 2152.7 & 2156.8 & 3706.4 & 3712.1 \\
\hline Time $(P)$ & $<0.0001$ & $<0.0001$ & $<0.0001$ & $<0.0001$ \\
\hline \multirow[t]{2}{*}{ Age $(P)$} & & 0.0621 & & 0.0836 \\
\hline & Female ALG & & Male ALG & \\
\hline $\begin{array}{l}\text { Model ChiSq } \\
(P<0.0001)\end{array}$ & 213.22 & 191.21 & 223.1 & 224.94 \\
\hline -2 log likelihood & 2287.4 & 2292.7 & 2964.9 & 2974 \\
\hline Time $(P)$ & $<0.0001$ & $<0.0001$ & $<0.0001$ & $<0.0001$ \\
\hline \multirow[t]{2}{*}{ Age $(P)$} & & 0.146 & & 0.8333 \\
\hline & Female PLG & & Male PLG & \\
\hline $\begin{array}{l}\text { Model ChiSq } \\
(P<0.0001)\end{array}$ & 177.37 & 151.74 & 205.7 & 207.85 \\
\hline-2 log likelihood & 1744.4 & 1749.7 & 3032.6 & 3041.8 \\
\hline Time $(P)$ & 0.0005 & 0.0005 & $<0.0001$ & $<0.0001$ \\
\hline Age $(P)$ & & 0.0928 & & 0.9854 \\
\hline
\end{tabular}

Overall model chi square (ChiSq) was always significant $(P<0.0001)$. The model fit is indicated by $-2 \times \log$ likelihood as calculated by SAS (higher indicates better fit). The $P$ values for each variable are shown; time was significant $(P<0.05)$ in all cases apart from male ASG and female MSG, and age was not significant in any model.

at least as measured by percent change. Other challenges have been reported to also elicit sex differences in insular responses; lower body negative pressure leads to greater right, but not left insular activity in males compared with females (94), and a hand grip task leads to higher right-sided responses in males compared with females (95). The reasons for greater insula deactivation to the Valsalva maneuver in males are unclear, but could reflect a different baseline state or a different neural response. Cerebral blood flow (CBF) differs by sex, but in young adults, the insula shows lower metabolism in females compared with males (96).

\section{Lateralization}

The lateralized organization of the insular responses in all but the anterior-most gyri showed greater right-side activation during Phase II of the Valsalva in both males and females, consistent with a preferentially sympathetic role of the right over left insula (73-76). The same patterns appeared in a combined female/ male group (44). Similarly, left-sided insula injury is associated with greater parasympathetic than sympathetic impairment $(97,98)$. In some circumstances, the rat posterior insula shows no lateralization of cardiovascular function in response to stimulation (90); while differences between rat and humans (74) may extend to lateralization, these recent data, nevertheless, show that the insula has complex topographic organizational and different response patterns arise from different stimulation types. The two hemispheres also show strong connections in the anterior insula (99). Nevertheless, human stroke findings are consistent with a right-sided sympathetic regulatory role $(28,100,101)$. Resection of the right insula due to the presence of a tumor also results in greater parasympathetic activity (38). Functional responses to a hand grip challenge also show right-sided dominance during sympathetic phases, for both left- and right-handed tasks (102). Further support is provided by a meta-analysis of neuroimaging findings (36). The present findings support a right-sided sympathetic dominance for at least some types of autonomic regulation, including, in this case, increased intrathoracic pressure.

\section{Anterior Sympathetic Dominance}

During the sympathetic-dominant Phase II of the Valsalva, the anterior gyri showed greater fMRI responses compared with posterior gyri, with the exception of the ASG in female subjects. Other imaging studies show similar preferentially anterior insular roles in physiologic responses (103). At a cellular level, the rat insula shows varying structure and propagation properties in the rostral-caudal direction [equivalent of anterior-posterior in humans $(23,104)]$, consistent with varying functional topography. Anterior function is more closely associated with visceral reactivity in the rat (40). Some of the original evidence supporting lateralization of sympathetic and parasympathetic function was based on right anterior insula stimulation, showing HR increases in rats (74). Supporting these earlier animal findings, in a healthy adult human population (males and females combined), the Valsalva shows a distinct right-sided dominance during the sympathetic Phase II period (44). Sex differences in the anterior-dominant sympathetic roles are highlighted by lower body negative pressure studies, which elicit greater right anterior insular activity in males than females, together with different physiological responses (94); males also showed greater reductions in left anterior insular activity. The present findings, in all but the right ASG in females, are thus consistent with current understanding of anterior-posterior distribution of autonomic function.

\section{Sources of Sex Differences in Brain Function}

A number of sex-based structural issues may contribute to the regional variation in functional responses found here. The middle short gyrus (MSG) in males is more distinct than in females; this sub-region was also more distinct in the left hemisphere, suggesting other sex and laterality variations (16). Females show higher gray matter volume in the right insular cortex than males (58). However, males show a greater number of distinct gyri on average [ 4.7 vs. 4.1 (48)]. Insular fibers also vary by sex; these fibers are influenced during development by hormonal status (105), specifically, connections between the left insula and left 

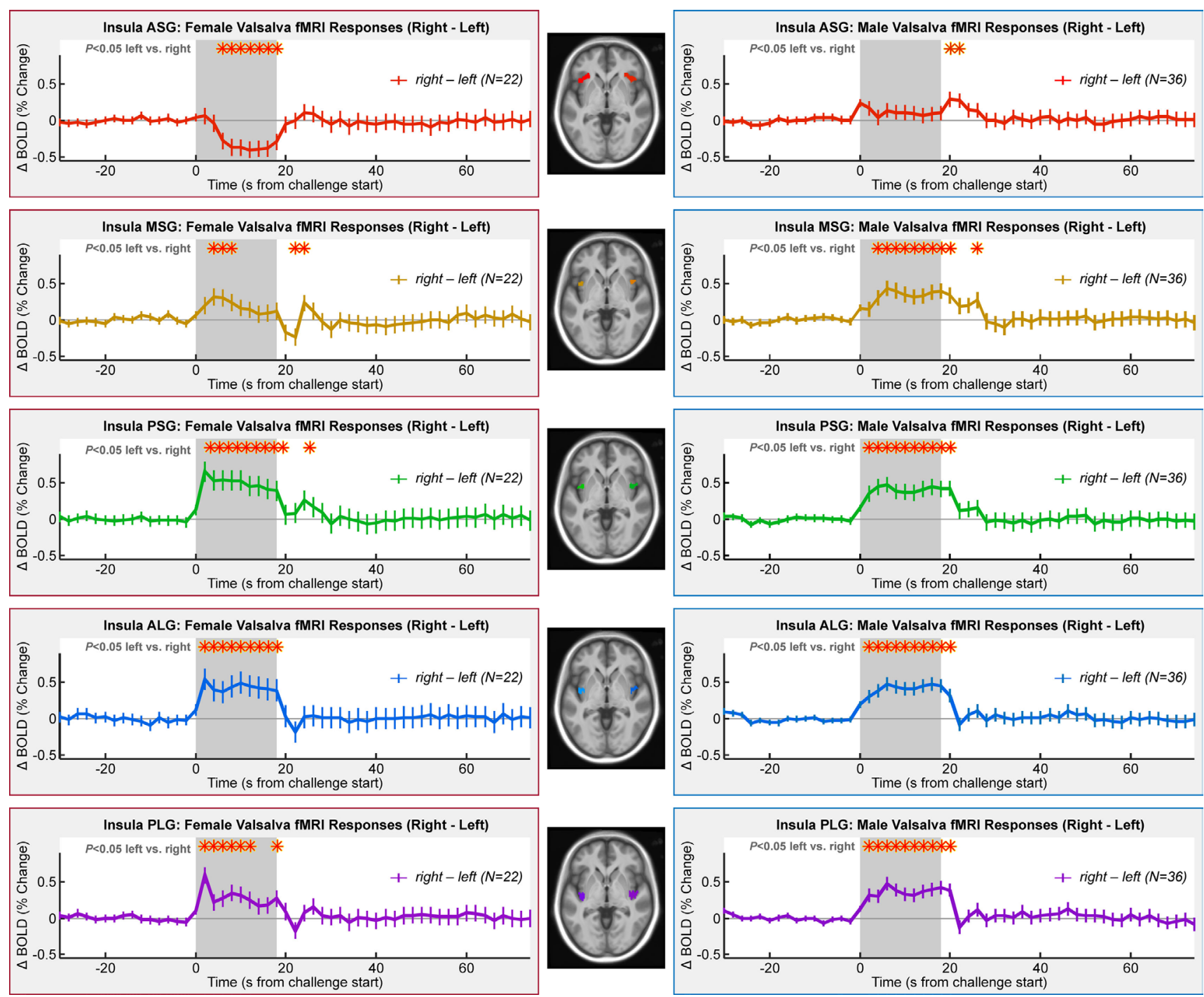

FIGURE 5 | Lateralization of insula fMRI responses over four Valsalva maneuvers, illustrated by right-left time trends, such that a higher signal indicates a greater right-sided response. Females in left column and males in right column. Timepoints of between-hemisphere differences are indicated by a red * above the graphs (RMANOVA, $P<0.05$ ).

precentral gyrus show a lower density during development in females vs. males (106). In addition to structural differences, insular metabolism in young adults is lower in females, compared with males, but this difference is reduced in more posterior regions (96).

The global sex differences in functional responses could arise from varied sources, including metabolism, CBF, and hormone levels, as well as functional state. Sex hormones influence function (107-109) and have neuroprotective effects (110). CBF is higher in females than males, and activity-related CBF changes vary by sex $(111,112)$. Metabolism shows variation by sex in the parietal cortex and ventrolateral prefrontal cortices in adults (113), as well as the insula in adolescents (96). Brain functional state likely also differs between females and males in the insula; for example, both basal state and stress responses mediated by the hypothalamic-pituitary-adrenal axis show extensive sex variations (114). The sex differences in these physiologic variables likely lead to sex differences in baseline state and responsiveness of insula function.

\section{Differentiating the Right ASG}

The anterior-most ASG showed patterns distinct from other female gyral responses as well as from male ASG responses. Since the HR changes were similar between sexes, this lateralization difference reflects either a differing baseline state or an altered organization. Considering the activation differences extend across all gyri, females and males may differ both by baseline state and by organization on the anterior short gyri. This altered organization of the anterior gyri was also reflected in within-structure, anterior-to-posterior organization, but with 
the differences appearing principally on the right side, with the anterior and mid short gyri showing relatively lower fMRI signals in females, in contrast with the higher activation in males. On the left side, both sexes demonstrate greater anterior gyral activation. The combined findings, therefore, suggest differing organization between females and males of the right ASG only, as opposed to differing baseline states.

\section{Clinical Implications}

A range of behavioral and physiological characteristics are mediated by insular structural and functional properties. The sex-based variations in the structure may mediate mechanisms underlying significant health issues. The blood pressure regulatory roles served by the insula likely contribute to the higher lifetime risk of stroke in women over men, with that preference principally found in older women (115). Age-related findings may directly reflect developmental changes in neural maturation or later in neuropathology unique to the insula. Alterations of the insular cortices appear prominently in structural MRI studies of depression, and women are twice as likely to experience depression signs (116). The insula is frequently implicated in anxiety $(117,118)$, and women show more prevalent and more disabling anxiety disorders (119). The incidence of migraine is higher in females (120), and the insula serves a significant role in integration of pain signals (121). Thus, differences in the integrity of structure and function of the insula by sex should be considered in evaluation of central contributions to multiple medical disorders.

\section{The fMRI Signal and $\mathrm{SaO}_{2}$ Influences}

The fMRI BOLD signal is influenced by baseline factors and changes in cerebral blood volume and metabolism and thus is not necessarily only a measure of neural activity. Sex differences in $\mathrm{SaO}_{2}$ included slightly higher baseline and recovery levels and a deeper fall and larger overshoot during recovery. Since fMRI signals are sensitive to baseline blood oxygenation, these differences in $\mathrm{SaO}_{2}$ could have influenced the findings (122). Conceivable, a higher $\mathrm{SaO}_{2}$ could lead to a ceiling effect for the females relative to males and thus limit the possible magnitude of signal change as seen in Figure 3; however, if all factors are equal, a higher baseline BOLD level would result in a larger signal change (122). The dynamic sex differences in $\mathrm{SaO}_{2}$ response are unlikely to have influenced the left-right or anterior-posterior differences since those effects occurred later in the challenge and lasted into the recovery period. Furthermore, global blood oxygenation levels as measured with a pulse oximeter would affect all regions similarly and thus should not contribute to region-specific variation. A final consideration is that challenges such as the Valsalva that elicit large changes in blood pressure lead to CBF and volume changes that dominate over oxygenation and neuronal activity influences, and variations in both baseline and responses of vascular state could have differed by sex. Such influences are by their nature global and could have influenced the consistent magnitude sex differences (Figure 3), but the left-right and anterior posterior differences (Figures 4 and 5) should principally reflect neuronal factors.

\section{Age Influences}

There may be a modest confound of age since the sample was not exactly aged matched, with females being older albeit not significantly so (50.0 vs. 45.3 years, $P=0.06$ ). Females in particular show changes in autonomic function associated with age and menopause $(84,123)$. However, although age impacts autonomic function, indices of the Valsalva maneuver, such as the Valsalva ratio, vary little or not at all with age $(1,65)$. If the sex differences were primarily due to age, the HR alterations should also show large sex differences. However, visual inspection of the magnitude of HR differences (Figure 2) relative to the fMRI differences (Figures 3-5) shows the cardiovascular responses differ only modestly, whereas the fMRI signals vary substantially, sometimes in opposite directions. The Valsalva challenge is therefore eliciting a similar albeit not equal peripheral response, but with substantial differences in neural response. Confirming the minimal influence of age, the inclusion of this variable in the RMANOVA models did not alter the patterns of difference in any model.

\section{Limitations}

The sample included left-handed, right-handed, and ambidextrous subjects; since handedness is associated with variations in some autonomic measures, such as QRS-T interval (124) and MSNA responses, although not cardiovascular responses to hand grip $(125,126)$, this factor may have confounded the findings. Since the handedness distribution was similar between sexes, the effect is likely to be one of increasing variability and reducing sensitivity to differences (i.e., increase false negatives). Menopausal status menstrual cycle stage and hormonal contraceptive use were erroneously not assessed, but the sample likely includes pre-, peri-, and post-menopausal women. Since menopausal status and stage of the menstrual cycle influence many aspects of autonomic function $(84,123)$, the female measures may have been confounded by hormonal influences. Such effects would likely increase variability in the female group, which would reduce statistical sensitivity; thus, the sex differences reported here are unlikely to be false positives. We assessed topography distinguished by gyri, which run essentially anterior-posterior, but there is likely also functional differentiation across an approximate inferior-superior direction, given the cytoarchitectonic gradient in the insula from agranular cortex in the (inferior) anterior part to dysgranular cortex in the middle part to granular cortex in the posterior part (127-129). However, clear topographical distinctions based on MRI scans beyond gyri are likely to remain complex, given the heterogeneity of this structure (130-132). The short gyri, in particular, are not always distinct $(16,48)$; thus, the classifications ASG, MSG, and PSG should be considered to refer to adjacent regions that, in some subjects, are not distinguished by a gyral fold. Our focus in the present study was gyral-specific patterns, but variations in function or vascular responses across hemispheres could be assessed using similar models with the addition of hemisphere as a factor. Other limitations include the relative nature of fMRI signals such that only functional responses can be measured, but not baseline activity. Functional responses are 
measured as regional blood volume and oxygenation changes, which while strongly associated with neuronal activity (133), are also influenced by whole-brain cerebral vasculature. However, such global effects would not alter the between-gryi and lateralization organizational patterns identified in the current study.

\section{CONCLUSION}

The insula shows sex differences in the topographic organization of functional responses during the sympathetic phase of the Valsalva maneuver. The response patterns are consistent with a principally inhibitory role for the structure. While the preferentially anterior autonomic function and preferentially righted sided sympathetic roles for the insula are shared in males and females, females show a smaller magnitude of change in fMRI signals than males in insular gyri. The exception is the right anteriormost gyrus (ASG) in females, which shows lower responses, compared with other female right and left anterior gyri, and compared with male gyri. The sex differences reflect altered baseline state and magnitude of responses and likely contribute to sex-related variations in autonomic responsiveness to some stimuli.

\section{REFERENCES}

1. Ndayisaba JP, Fanciulli A, Granata R, Duerr S, Hintringer F, Goebel G, et al. Sex and age effects on cardiovascular autonomic function in healthy adults. Clin Auton Res (2015) 25:317-26. doi:10.1007/s10286-015-0310-1

2. Merz AA, Cheng S. Sex differences in cardiovascular ageing. Heart (2016) 102(11):825-31. doi:10.1136/heartjnl-2015-308769

3. Boynton RE, Todd RL. Blood pressure readings of 75,258 university students. Arch Intern Med (Chic) (1947) 80:454-62. doi:10.1001/archinte.1947. 00220160033003

4. Stamler J, Stamler R, Riedlinger WF, Algera G, Roberts RH. Hypertension screening of 1 million Americans. Community hypertension evaluation clinic (CHEC) program, 1973 through 1975. JAMA (1976) 235:2299-306. doi:10.1001/jama.1976.03260470017018

5. Narkiewicz K, Phillips BG, Kato M, Hering D, Bieniaszewski L, Somers VK. Gender-selective interaction between aging, blood pressure, and sympathetic nerve activity. Hypertension (2005) 45:522-5. doi:10.1161/01. HYP.0000160318.46725.46

6. Greenland P, Reicher-Reiss H, Goldbourt U, Behar S. In-hospital and 1 -year mortality in 1,524 women after myocardial infarction. Comparison with 4,315 men. Circulation (1991) 83:484-91. doi:10.1161/01.CIR.83. 2.484

7. Tunstall-Pedoe H, Kuulasmaa K, Amouyel P, Arveiler D, Rajakangas AM, Pajak A. Myocardial infarction and coronary deaths in the World Health Organization MONICA project. Registration procedures, event rates, and case-fatality rates in 38 populations from 21 countries in four continents. Circulation (1994) 90:583-612. doi:10.1161/01.CIR.90.1.583

8. Ng AV, Callister R, Johnson DG, Seals DR. Age and gender influence muscle sympathetic nerve activity at rest in healthy humans. Hypertension (1993) 21:498-503. doi:10.1161/01.HYP.21.4.498

9. Matsukawa T, Sugiyama Y, Watanabe T, Kobayashi F, Mano T. Gender difference in age-related changes in muscle sympathetic nerve activity in healthy subjects. Am J Physiol (1998) 275:R1600-4.

10. Liao D, Barnes RW, Chambless LE, Simpson RJ Jr, Sorlie P, Heiss G. Age, race, and sex differences in autonomic cardiac function measured by spectral analysis of heart rate variability - the ARIC study. Atherosclerosis risk in communities. Am J Cardiol (1995) 76:906-12. doi:10.1016/S00029149(99)80260-4

\section{AUTHOR NOTE}

The mechanism of the tachycardia during the maneuver remains controversial, some workers suggesting exclusive enhancement of sympathetic activity and others suggesting depression of parasympathetic outflow; also, both parasympathetic withdrawal and increased sympathetic outflow have been suggested (Bennett et al., 1976; Eckberg, 1980). The quantification of heart interval variations [P65 (Junqueira, 2002)] impaired autonomic control of heart Valsalva.

\section{AUTHOR CONTRIBUTIONS}

Conception or design: RH, PM, and MW. Acquisition: RH, RK, PM, and MW. Analysis: PM, NR, and PW. Interpretation: RH, RK, HM, PM, JO, and NR. All authors contributed to the manuscript and approved the final version, and all authors agree to be accountable for the work.

\section{FUNDING}

This work was supported by the NIH National Institute of Nursing Research NR013693.

11. Del Rio G, Verlardo A, Zizzo G, Marrama P, Della Casa L. Sex differences in catecholamine response to clonidine. Int J Obes Relat Metab Disord (1993) 17:465-9.

12. Abdel-Rahman AR, Merrill RH, Wooles WR. Gender-related differences in the baroreceptor reflex control of heart rate in normotensive humans. J Appl Physiol (1985) (1994) 77:606-13.

13. Dart AM, Du XJ, Kingwell BA. Gender, sex hormones and autonomic nervous control of the cardiovascular system. Cardiovasc Res (2002) 53:678-87. doi:10.1016/S0008-6363(01)00508-9

14. Hinojosa-Laborde C, Chapa I, Lange D, Haywood JR. Gender differences in sympathetic nervous system regulation. Clin Exp Pharmacol Physiol (1999) 26:122-6. doi:10.1046/j.1440-1681.1999.02995.x

15. Cosgrove KP, Mazure CM, Staley JK. Evolving knowledge of sex differences in brain structure, function, and chemistry. Biol Psychiatry (2007) 62:847-55. doi:10.1016/j.biopsych.2007.03.001

16. Rosen A, Chen DQ, Hayes DJ, Davis KD, Hodaie M. A neuroimaging strategy for the three-dimensional in vivo anatomical visualization and characterization of insular gyri. Stereotact Funct Neurosurg (2015) 93:255-64 doi: $10.1159 / 000380826$

17. Landau E. The comparative anatomy of the nucleus amygdalae, the claustrum and the insular cortex. J Anat (1919) 53:351-60.

18. Ture U, Yasargil DC, Al-Mefty O, Yasargil MG. Topographic anatomy of the insular region. J Neurosurg (1999) 90:720-33. doi:10.3171/jns.1999.90.4.0720

19. Guenot M, Isnard J, Sindou M. Surgical anatomy of the insula. Adv Tech Stand Neurosurg (2004) 29:265-88. doi:10.1007/978-3-7091-0558-0_7

20. Oppenheimer S, Cechetto D. The insular cortex and the regulation of cardiac function. Compr Physiol (2016) 6:1081-133. doi:10.1002/cphy.c140076

21. Loewy AD. Descending pathways to the sympathetic preganglionic neurons. Prog Brain Res (1982) 57:267-77. doi:10.1016/s0079-6123(08)64133-3

22. Shipley MT. Insular cortex projection to the nucleus of the solitary tract and brainstem visceromotor regions in the mouse. Brain Res Bull (1982) 8:139-48. doi:10.1016/0361-9230(82)90040-5

23. Allen GV, Saper CB, Hurley KM, Cechetto DF. Organization of visceral and limbic connections in the insular cortex of the rat. J Comp Neurol (1991) 311:1-16. doi:10.1002/cne.903110102

24. Nagai M, Hoshide S, Kario K. The insular cortex and cardiovascular system: a new insight into the brain-heart axis. J Am Soc Hypertens (2010) 4:174-82. doi:10.1016/j.jash.2010.05.001 
25. Alves FH, Crestani CC, Resstel LB, Correa FM. N-methyl-D-aspartate receptors in the insular cortex modulate baroreflex in unanesthetized rats. Auton Neurosci (2009) 147:56-63. doi:10.1016/j.autneu.2008.12.015

26. Saad MA, Huerta F, Trancard J, Elghozi JL. Effects of middle cerebral artery occlusion on baroreceptor reflex control of heart rate in the rat. J Auton Nerv Syst (1989) 27:165-72. doi:10.1016/0165-1838(89)90098-2

27. Esler MD, Lambert GW, Ferrier C, Kaye DM, Wallin BG, Kalff V, et al. Central nervous system noradrenergic control of sympathetic outflow in normotensive and hypertensive humans. Clin Exp Hypertens (1995) 17:409-23. doi:10.3109/10641969509087081

28. Oppenheimer SM, Kedem G, Martin WM. Left-insular cortex lesions perturb cardiac autonomic tone in humans. Clin Auton Res (1996) 6:131-40. doi:10.1007/BF02281899

29. Saleh TM, Connell BJ. Role of the insular cortex in the modulation of baroreflex sensitivity. Am J Physiol (1998) 274:R1417-24.

30. Verberne AJ, Owens NC. Cortical modulation of the cardiovascular system. Prog Neurobiol (1998) 54:149-68. doi:10.1016/S0301-0082(97)00056-7

31. Zhang ZH, Rashba S, Oppenheimer SM. Insular cortex lesions alter baroreceptor sensitivity in the urethane-anesthetized rat. Brain Res (1998) 813:73-81. doi:10.1016/S0006-8993(98)00996-2

32. Alves FH, Crestani CC, Resstel LB, Correa FM. Insular cortex alpha1adrenoceptors modulate the parasympathetic component of the baroreflex in unanesthetized rats. Brain Res (2009) 1295:119-26. doi:10.1016/j. brainres.2009.08.013

33. Gray MA, Rylander K, Harrison NA, Wallin BG, Critchley HD. Following one's heart: cardiac rhythms gate central initiation of sympathetic reflexes. J Neurosci (2009) 29:1817-25. doi:10.1523/JNEUROSCI.3363-08.2009

34. Nagai M, Hoshide S, Ishikawa J, Shimada K, Kario K. Insular cortex atrophy as an independent determinant of disrupted diurnal rhythm of ambulatory blood pressure in elderly hypertension. Am J Hypertens (2009) 22:723-9. doi:10.1038/ajh.2009.71

35. Alves FH, Crestani CC, Resstel LB, Correa FM. Cardiovascular effects of noradrenaline microinjected into the insular cortex of unanesthetized rats. Auton Neurosci (2011) 160:90-8. doi:10.1016/j.autneu.2010.11.002

36. Beissner F, Meissner K, Bar KJ, Napadow V. The autonomic brain: an activation likelihood estimation meta-analysis for central processing of autonomic function. J Neurosci (2013) 33:10503-11. doi:10.1523/JNEUROSCI. 1103-13.2013

37. Tayah T, Savard M, Desbiens R, Nguyen DK. Ictal bradycardia and asystole in an adult with a focal left insular lesion. Clin Neurol Neurosurg (2013) 115:1885-7. doi:10.1016/j.clineuro.2013.04.011

38. De Morree HM, Rutten GJ, Szabo BM, Sitskoorn MM, Kop WJ. Effects of insula resection on autonomic nervous system activity. J Neurosurg Anesthesiol (2016) 28:153-8. doi:10.1097/ANA.0000000000000207

39. Scheitz JF, Erdur H, Haeusler KG, Audebert HJ, Roser M, Laufs U, et al. Insular cortex lesions, cardiac troponin, and detection of previously unknown atrial fibrillation in acute ischemic stroke: insights from the troponin elevation in acute ischemic stroke study. Stroke (2015) 46:1196-201. doi:10.1161/ STROKEAHA.115.008681

40. Cechetto DF, Saper CB. Evidence for a viscerotopic sensory representation in the cortex and thalamus in the rat. J Comp Neurol (1987) 262:27-45. doi:10.1002/cne.902620104

41. Dupont S, Bouilleret V, Hasboun D, Semah F, Baulac M. Functional anatomy of the insula: new insights from imaging. Surg Radiol Anat (2003) 25:113-9. doi:10.1007/s00276-003-0103-4

42. Kurth F, Zilles K, Fox PT, Laird AR, Eickhoff SB. A link between the systems: functional differentiation and integration within the human insula revealed by meta-analysis. Brain Struct Funct (2010) 214:519-34. doi:10.1007/ s00429-010-0255-z

43. Stephani C, Fernandez-Baca Vaca G, Maciunas R, Koubeissi M, Luders HO. Functional neuroanatomy of the insular lobe. Brain Struct Funct (2011) 216:137-49. doi:10.1007/s00429-010-0296-3

44. Macey PM, Wu P, Kumar R, Ogren JA, Richardson HL, Woo MA, et al. Differential responses of the insular cortex gyri to autonomic challenges. Auton Neurosci (2012) 168:72-81. doi:10.1016/j.autneu.2012.01.009

45. Craig AD. Topographically organized projection to posterior insular cortex from the posterior portion of the ventral medial nucleus in the long-tailed macaque monkey. J Comp Neurol (2014) 522:36-63. doi:10.1002/cne.23425
46. Shura RD, Hurley RA, Taber KH. Insular cortex: structural and functional neuroanatomy. J Neuropsychiatry Clin Neurosci (2014) 26:276-82. doi:10.1176/appi.neuropsych.260401

47. Macey PM, Kumar R, Woo MA, Yan-Go FL, Harper RM. Heart rate responses to autonomic challenges in obstructive sleep apnea. PLoS One (2013) 8:e76631. doi:10.1371/journal.pone.0076631

48. Mavridis I, Boviatsis E, Anagnostopoulou S. Exploring the neurosurgical anatomy of the human insula: a combined and comparative anatomicradiologic study. Surg Radiol Anat (2011) 33:319-28. doi:10.1007/s00276010-0699-0

49. Peters M. Sex differences in human brain size and the general meaning of differences in brain size. Can J Psychol (1991) 45:507-22. doi:10.1037/ h0084307

50. SchluterD.Brainsizedifferences.Nature(1992)359:181.doi:10.1038/359181a0

51. Luders E, Gaser C, Narr KL, Toga AW. Why sex matters: brain size independent differences in gray matter distributions between men and women. J Neurosci (2009) 29:14265-70. doi:10.1523/JNEUROSCI.2261-09.2009

52. Luders E, Steinmetz H, Jancke L. Brain size and grey matter volume in the healthy human brain. Neuroreport (2002) 13:2371-4. doi:10.1097/01. wnr.0000049603.85580.da

53. Allen JS, Damasio H, Grabowski TJ, Bruss J, Zhang W. Sexual dimorphism and asymmetries in the gray-white composition of the human cerebrum. Neuroimage (2003) 18:880-94. doi:10.1016/S1053-8119(03)00034-X

54. Luders E, Narr KL, Thompson PM, Rex DE, Jancke L, Toga AW. Hemispheric asymmetries in cortical thickness. Cereb Cortex (2006) 16:1232-8. doi:10.1093/cercor/bhj064

55. Luders E, Narr KL, Thompson PM, Rex DE, Woods RP, Deluca H, et al. Gender effects on cortical thickness and the influence of scaling. Hum Brain Mapp (2006) 27:314-24. doi:10.1002/hbm.20187

56. Leonard CM, Towler S, Welcome S, Halderman LK, Otto R, Eckert MA, et al. Size matters: cerebral volume influences sex differences in neuroanatomy. Cereb Cortex (2008) 18:2920-31. doi:10.1093/cercor/bhn052

57. Luders E, Toga AW. Sex differences in brain anatomy. Prog Brain Res (2010) 186:3-12. doi:10.1016/B978-0-444-53630-3.00001-4

58. Ruigrok AN, Salimi-Khorshidi G, Lai MC, Baron-Cohen S, Lombardo MV, Tait RJ, et al. A meta-analysis of sex differences in human brain structure. Neurosci Biobehav Rev (2014) 39:34-50. doi:10.1016/j.neubiorev.2013.12.004

59. Macey PM, Ogren JA, Kumar R, Harper RM. Functional imaging of autonomic regulation: methods and key findings. Front Neurosci (2015) 9:513. doi:10.3389/fnins.2015.00513

60. Valsalva AM. De aure humana tractatus: in quo integra eiusdem aurius fabrica, multis novis inventis, \& iconismis illustrata, describitur, omniumque eius partium usus indagantur: quibus interposita est musculorum uvulae, atque pharyngis nova descriptio, et delineatio. Bononiae: Typis Constantini Pisarii (1704).

61. Luciani L, Welby FA, Camis M, Holmes G, Pembrey MS. Human Physiology. London: Macmillan and Co (1911).

62. Goldberg H, Elisberg EI, Katz LN. The effects of the Valsalva-like maneuver upon the circulation in normal individuals and patients with mitral stenosis. Circulation (1952) 5:38-47. doi:10.1161/01.CIR.5.1.38

63. Mudry A. Valsalva manoeuvre: a confusing dichotomatic misnomer. Int J Pediatr Otorhinolaryngol (2015) 79:1851-5. doi:10.1016/j.ijporl.2015.08.023

64. Luster EA, Baumgartner N, Adams WC, Convertino VA. Effects of hypovolemia and posture on responses to the Valsalva maneuver. Aviat Space Environ Med (1996) 67:308-13.

65. Low PA, Denq JC, Opfer-Gehrking TL, Dyck PJ, O'brien PC, Slezak JM. Effect of age and gender on sudomotor and cardiovagal function and blood pressure response to tiltin normalsubjects.MuscleNerve (1997)20:1561-8.doi:10.1002/ (SICI) 1097-4598(199712)20:12<1561::AID-MUS11>3.0.CO;2-3

66. Denq JC, O'brien PC, Low PA. Normative data on phases of the Valsalva maneuver. JClin Neurophysiol (1998) 15:535-40. doi:10.1097/00004691199811000-00013

67. Sandroni P, Benarroch EE, Low PA. Pharmacological dissection of components of the Valsalva maneuver in adrenergic failure. J Appl Physiol (1985) (1991) 71:1563-7.

68. Matsukawa T, Sugiyama Y, Watanabe T, Kobayashi F, Mano T. Baroreflex control of muscle sympathetic nerve activity is attenuated in the elderly. J Auton Nerv Syst (1998) 73:182-5. doi:10.1016/S0165-1838(98)00128-3 
69. Elisberg EI, Miller G, Weinberg SL, Katz LN. The effect of the Valsalva maneuver on the circulation. II. The role of the autonomic nervous system in the production of the overshoot. Am Heart J (1953) 45:227-36. doi:10.1016/0002-8703(53)90183-5

70. Ewing DJ. Cardiovascular reflexes and autonomic neuropathy. Clin Sci Mol Med (1978) 55:321-7.

71. Eckberg DL. Parasympathetic cardiovascular control in human disease: a critical review of methods and results. Am J Physiol (1980) 239:H581-93.

72. Pstras L, Thomaseth K, Waniewski J, Balzani I, Bellavere F. The Valsalva manoeuvre: physiology and clinical examples. Acta Physiol (Oxf) (2016) 217:103-19. doi:10.1111/apha.12639

73. Oppenheimer SM, Cechetto DF. Cardiac chronotropic organization of the rat insular cortex. Brain Res (1990) 533:66-72. doi:10.1016/0006-8993(90) 91796-J

74. Oppenheimer SM, Gelb A, Girvin JP, Hachinski VC. Cardiovascular effects of human insular cortex stimulation. Neurology (1992) 42:1727-32. doi:10.1212/WNL.42.9.1727

75. Zhang Z, Oppenheimer SM. Characterization, distribution and lateralization of baroreceptor-related neurons in the rat insular cortex. Brain Res (1997) 760:243-50. doi:10.1016/S0006-8993(97)00284-9

76. Zhang ZH, Dougherty PM, Oppenheimer SM. Characterization of baroreceptor-related neurons in the monkey insular cortex. Brain Res (1998) 796:303-6. doi:10.1016/S0006-8993(98)00268-6

77. Taylor D. The valsalva manoeuvre: a critical review. J South Pacific Underwater Med Soc (1996) 26:8-13.

78. Hutton C, Bork A, Josephs O, Deichmann R, Ashburner J, Turner R. Image distortion correction in fMRI: a quantitative evaluation. Neuroimage (2002) 16:217-40. doi:10.1006/nimg.2001.1054

79. Rorden C, Karnath HO, Bonilha L. Improving lesion-symptom mapping. J Cogn Neurosci (2007) 19:1081-8. doi:10.1162/jocn.2007.19.7.1081

80. Naidich TP, Kang E, Fatterpekar GM, Delman BN, Gultekin SH, Wolfe D, et al. The insula: anatomic study and MR imaging display at 1.5 T. AJNR Am J Neuroradiol (2004) 25:222-32.

81. Littell RC, Milliken GA, Stroup WW, Wolfinger RD. SAS System for Mixed Models. Cary, NC: SAS Institute Inc (1996).

82. Macey P, Schluter P, Macey K, Harper R. Detecting variable responses within fMRI time-series of volumes-of-interest using repeated measures ANOVA. F1000research (2016) 5:563. doi:10.12688/f1000research.8252.1

83. King AB, Menon RS, Hachinski V, Cechetto DF. Human forebrain activation by visceral stimuli. J Comp Neurol (1999) 413:572-82. doi:10.1002/ (SICI)1096-9861(19991101)413:4<572::AID-CNE6>3.0.CO;2-S

84. Lavi S, Nevo O, Thaler I, Rosenfeld R, Dayan L, Hirshoren N, et al. Effect of aging on the cardiovascular regulatory systems in healthy women. Am J Physiol Regul Integr Comp Physiol (2007) 292:R788-93. doi:10.1152/ ajpregu.00352.2006

85. Looga R. The bradycardic response to the Valsalva manoeuvre in normal man. Respir Physiol (2001) 124:205-15. doi:10.1016/S0034-5687(00)00216-4

86. Macey P. Summary fMRI and Physiology Data from Valsalva Maneuver in Female and Male Healthy Subjects. Harvard Dataverse (2016).

87. Storm DS, Metzger BL, Therrien B. Effects of age on autonomic cardiovascular responsiveness in healthy men and women. Nurs Res (1989) 38:326-30. doi:10.1097/00006199-198911000-00002

88. Barron SA, Rogovski Z, Hemli J. Autonomic consequences of cerebral hemisphere infarction. Stroke (1994) 25:113-6. doi:10.1161/01.STR.25.1.113

89. Oppenheimer S. Cerebrogenic cardiac arrhythmias: cortical lateralization and clinical significance. Clin Auton Res (2006) 16:6-11. doi:10.1007/ s10286-006-0276-0

90. Marins FR, Limborco-Filho M, Xavier CH, Biancardi VC, Vaz GC, Stern JE, et al. Functional topography of cardiovascular regulation along the rostrocaudal axis of the rat posterior insular cortex. Clin Exp Pharmacol Physiol (2016) 43(4):484-93. doi:10.1111/1440-1681.12542

91. Butcher KS, Cechetto DF. Neurotransmission in the medulla mediating insular cortical and lateral hypothalamic sympathetic responses. Can J Physiol Pharmacol (1998) 76:737-46. doi:10.1139/y98-082

92. Butcher KS, Cechetto DF. Receptors in lateral hypothalamic area involved in insular cortex sympathetic responses. Am J Physiol (1998) 275:H689-96.

93. Meyer S, Strittmatter M, Fischer C, Georg T, Schmitz B. Lateralization in autonomic dysfunction in ischemic stroke involving the insular cortex. Neuroreport (2004) 15:357-61. doi:10.1097/00001756-200402090-00029
94. Kimmerly DS, Wong S, Menon R, Shoemaker JK. Forebrain neural patterns associated with sex differences in autonomic and cardiovascular function during baroreceptor unloading. Am J Physiol Regul Integr Comp Physiol (2007) 292:R715-22. doi:10.1152/ajpregu.00366.2006

95. Wong SW, Kimmerly DS, Masse N, Menon RS, Cechetto DF, Shoemaker JK. Sex differences in forebrain and cardiovagal responses at the onset of isometric handgrip exercise: a retrospective fMRI study. J Appl Physiol (1985) (2007) 103:1402-11. doi:10.1152/japplphysiol.00171.2007

96. Hu Y, Xu Q, Shen J, Li K, Zhu H, Zhang Z, et al. Small-worldness and gender differences of large scale brain metabolic covariance networks in young adults: a FDG PET study of 400 subjects. Acta Radiol (2015) 56:204-13. doi:10.1177/0284185114529106

97. Hilz MJ, Dutsch M, Perrine K, Nelson PK, Rauhut U, Devinsky O. Hemispheric influence on autonomic modulation and baroreflex sensitivity. Ann Neurol (2001) 49:575-84. doi:10.1002/ana.1006

98. Sykora M, Diedler J, Turcani P, Hacke W, Steiner T. Baroreflex: a new therapeutic target in human stroke? Stroke (2009) 40:e678-82. doi:10.1161/ STROKEAHA.109.565838

99. Lacuey N, Zonjy B, Kahriman ES, Marashly A, Miller J, Lhatoo SD, et al. Homotopic reciprocal functional connectivity between anterior human insulae. Brain Struct Funct (2016) 221:2695-701. doi:10.1007/s00429-015-1065-0

100. Oppenheimer SM, Hachinski VC. The cardiac consequences of stroke. Neurol Clin (1992) 10:167-76.

101. Bar KJ, Berger S, Schwier C, Wutzler U, Beissner F. Insular dysfunction and descending pain inhibition in anorexia nervosa. Acta Psychiatr Scand (2013) 127:269-78. doi:10.1111/j.1600-0447.2012.01896.x

102. Wong SW, Masse N, Kimmerly DS, Menon RS, Shoemaker JK. Ventral medial prefrontal cortex and cardiovagal control in conscious humans. Neuroimage (2007) 35:698-708. doi:10.1016/j.neuroimage.2006.12.027

103. Mutschler I, Wieckhorst B, Kowalevski S, Derix J, Wentlandt J, SchulzeBonhage A, et al. Functional organization of the human anterior insular cortex. Neurosci Lett (2009) 457:66-70. doi:10.1016/j.neulet.2009.03.101

104. Adachi K, Fujita S, Yoshida A, Sakagami H, Koshikawa N, Kobayashi M. Anatomical and electrophysiological mechanisms for asymmetrical excitatory propagation in the rat insular cortex: in vivo optical imaging and whole-cell patch-clamp studies. J Comp Neurol (2013) 521:1598-613. doi: $10.1002 /$ cne. 23246

105. Herting MM, Maxwell EC, Irvine C, Nagel BJ. The impact of sex, puberty, and hormones on white matter microstructure in adolescents. Cereb Cortex (2012) 22:1979-92. doi:10.1093/cercor/bhr246

106. Dennis EL, Jahanshad N, McMahon KL, De Zubicaray GI, Martin NG, Hickie IB, et al. Development of insula connectivity between ages 12 and 30 revealed by high angular resolution diffusion imaging. Hum Brain Mapp (2014) 35:1790-800. doi:10.1002/hbm.22292

107. Saleh TM, Connell BJ, Legge C, Cribb AE. Estrogen attenuates neuronal excitability in the insular cortex following middle cerebral artery occlusion. Brain Res (2004) 1018:119-29. doi:10.1016/j.brainres.2004.05.074

108. Saleh TM, Connell BJ. Role of oestrogen in the central regulation of autonomic function. Clin Exp Pharmacol Physiol (2007) 34:827-32. doi:10.1111/j.1440-1681.2007.04663.x

109. Hwang MJ, Zsido RG, Song H, Pace-Schott EF, Miller KK, Lebron-Milad K, et al. Contribution of estradiol levels and hormonal contraceptives to sex differences within the fear network during fear conditioning and extinction. BMC Psychiatry (2015) 15:295. doi:10.1186/s12888-015-0673-9

110. Saleh MC, Connell BJ, Saleh TM. Resveratrol induced neuroprotection is mediated via both estrogen receptor subtypes, ER(alpha) and ER(beta). Neurosci Lett (2013) 548:217-21. doi:10.1016/j.neulet.2013.05.057

111. Gur RC, Gur RE, Obrist WD, Hungerbuhler JP, Younkin D, Rosen AD, et al. Sex and handedness differences in cerebral blood flow during rest and cognitive activity. Science (1982) 217:659-61. doi:10.1126/science. 7089587

112. Rodriguez G, Warkentin S, Risberg J, Rosadini G. Sex differences in regional cerebral blood flow. J Cereb Blood Flow Metab (1988) 8:783-9. doi:10.1038/ jcbfm.1988.133

113. Kakimoto A, Ito S, Okada H, Nishizawa S, Minoshima S, Ouchi Y. Age-related sex-specific changes in brain metabolism and morphology. J Nucl Med (2016) 57:221-5. doi:10.2967/jnumed.115.166439

114. Goel N, Workman JL, Lee TT, Innala L, Viau V. Sex differences in the HPA axis. Compr Physiol (2014) 4:1121-55. doi:10.1002/cphy.c130054 
115. Rosamond W, Flegal K, Furie K, Go A, Greenlund K, Haase N, et al. Heart disease and stroke statistics-2008 update - a report from the American Heart Association Statistics Committee and Stroke Statistics Subcommittee. Circulation (2008) 117:E25-146. doi:10.1161/Circulationaha.107.187998

116. Nolen-Hoeksema S. Gender differences in depression. Curr Dir Psychol Sci (2001) 10:173-6. doi:10.1111/1467-8721.00142

117. Kumar R, Macey PM, Cross RL, Woo MA, Yan-Go FL, Harper RM. Neural alterations associated with anxiety symptoms in obstructive sleep apnea syndrome. Depress Anxiety (2009) 26:480-91. doi:10.1002/da. 20531

118. Kawaguchi A, Nemoto K, Nakaaki S, Kawaguchi T, Kan H, Arai N, et al. Insular volume reduction in patients with social anxiety disorder. Front Psychiatry (2016) 7:3. doi:10.3389/fpsyt.2016.00003

119. McLean CP, Asnaani A, Litz BT, Hofmann SG. Gender differences in anxiety disorders: prevalence, course of illness, comorbidity and burden of illness. J Psychiatr Res (2011) 45:1027-35. doi:10.1016/j.jpsychires.2011. 03.006

120. Maleki N, Barmettler G, Moulton EA, Scrivani S, Veggeberg R, Spierings EL, et al. Female migraineurs show lack of insular thinning with age. Pain (2015) 156:1232-9. doi:10.1097/j.pain.0000000000000159

121. Henderson LA, Rubin TK, Macefield VG. Within-limb somatotopic representation of acute muscle pain in the human contralateral dorsal posterior insula. Hum Brain Mapp (2011) 32:1592-601. doi:10.1002/hbm. 21131

122. Kim SG, Ogawa S. Biophysical and physiological origins of blood oxygenation level-dependent fMRI signals. J Cereb Blood Flow Metab (2012) 32:1188-206. doi:10.1038/jcbfm.2012.23

123. Vallejo M, Marquez MF, Borja-Aburto VH, Cardenas M, Hermosillo AG. Age, body mass index, and menstrual cycle influence young women's heart rate variability - a multivariable analysis. Clin Auton Res (2005) 15:292-8. doi:10.1007/s10286-005-0272-9

124. Iscen S, Ozenc S, Tavlasoglu U. Association between left-handedness and cardiac autonomic function in healthy young men. Pacing Clin Electrophysiol (2014) 37:884-8. doi:10.1111/pace.12365

125. Saito M. Exercise-induced sympathetic activation is correlated with cerebral hemisphere laterality, but not handedness. Acta Physiol Scand (2000) 170:111-8. doi:10.1046/j.1365-201x.2000.00764.x
126. Saito M, Kato M, Mano T. Comparison of sympathetic nerve activity during handgrip exercise performed with the dominant and non-dominant arm. Environ Med (2000) 44:60-2.

127. Mesulam MM, Mufson EJ. Insula of the old world monkey. I. Architectonics in the insulo-orbito-temporal component of the paralimbic brain. J Comp Neurol (1982) 212:1-22. doi:10.1002/cne.902120102

128. Klein TA, Ullsperger M, Danielmeier C. Error awareness and the insula: links to neurological and psychiatric diseases. Front Hum Neurosci (2013) 7:14. doi:10.3389/fnhum.2013.00014

129. Morel A, Gallay MN, Baechler A, Wyss M, Gallay DS. The human insula: architectonic organization and postmortem MRI registration. Neuroscience (2013) 236:117-35. doi:10.1016/j.neuroscience.2012.12.076

130. Cauda F, Costa T, Torta DM, Sacco K, D'agata F, Duca S, et al. Meta-analytic clustering of the insular cortex: characterizing the meta-analytic connectivity of the insula when involved in active tasks. Neuroimage (2012) 62:343-55. doi:10.1016/j.neuroimage.2012.04.012

131. Nieuwenhuys R. The insular cortex: a review. Prog Brain Res (2012) 195:123-63. doi:10.1016/B978-0-444-53860-4.00007-6

132. Evrard HC, Logothetis NK, Craig AD. Modular architectonic organization of the insula in the macaque monkey. J Comp Neurol (2014) 522:64-97. doi:10.1002/cne.23436

133. Logothetis NK, Pauls J, Augath M, Trinath T, Oeltermann A. Neurophysiological investigation of the basis of the fMRI signal. Nature (2001) 412:150-7. doi: $10.1038 / 35084005$

Conflict of Interest Statement: The authors declare that the research was conducted in the absence of any commercial or financial relationships that could be construed as a potential conflict of interest.

Copyright (C) 2016 Macey, Rieken, Kumar, Ogren, Middlekauff, Wu, Woo and Harper. This is an open-access article distributed under the terms of the Creative Commons Attribution License (CC BY). The use, distribution or reproduction in other forums is permitted, provided the original author(s) or licensor are credited and that the original publication in this journal is cited, in accordance with accepted academic practice. No use, distribution or reproduction is permitted which does not comply with these terms. 